\title{
Leistungsfähige Keramik
}

Auch wenn die Hitze in diesem Sommer so manchen Europäer reichlich schwitzen ließ, der Keramikbranche macht sie bekanntlich eher nicht zu schaffen. Die Unternehmen bereiten sich auf die bevorstehenden Messen und Konferenzen vor. Denn im September findet die Tecnargilla im italienischen Rimini statt, zeitgleich das 61. Internationale Feuerfest-Kolloquium in Aachen und im Oktober dann die glasstec in Düsseldorf um nur ein paar Beispiele zu nennen.

Die Hersteller von Keramik- und Glasprodukten und ihre Zulieferer zeigen sich leistungsfähig. Innovationspreise wurden verliehen und Forschungsaktivitäten ausgezeichnet. Zudem steht der Semesterbeginn für die Studierenden im Herbst bevor. Zunehmender Beliebtheit erfreut sich u. a. das Duale Studium. Am WesterWaldCampus in Höhr-Grenzhausen wird es im Oktober 2018 erstmals angeboten. Die Hochschule Koblenz setzt dort im Bereich Werkstoffwissenschaften, Glas \& Keramik auf die Verknüpfung von Forschung \& Lehre mit Industrie \& Ausbildung - für viele Unternehmen sicher ein Gewinn.

Mit ihren Forschungsprojekten auf dem neuesten Stand zu sein, ist stets erstes Ziel der Hochschulen und Forschungsinstitute. So wurde in Aalen ein neuer 3D-Drucker angeschafft. Die Hochschule forscht dort im Bereich Additive Fertigung bei Hochleistungskeramiken und Hartmetallen und wird sich mit ,smarten Materialien und intelligenten Produktionstechnologien für energieeffiziente Produkte“ beschäftigen. 3D-Druck ist Innovationsbeschleuniger, heißt es beim Digitalverband Bitkom und: „Die Technologie bietet die Chance, in Niedriglohnländer abgewanderte Wertschöpfung nach Deutschland zurückzuziehen."

Mehr über Entwicklungen und Trends erfahren Sie außerdem im Nachgang zur DKG-Jahrestagung, und zum Freiberger Feuerfestkolloquium. Es folgt ein Fachbeitrag über die Herstellung von Feuerfestmaterial durch Druckschlickerguss.

Zuletzt starten wir eine dreiteilige Serie über pulvertechnisch hergestellte Werkstoffe für die Elektromobilität von Morgen. Denn es gibt zahlreiche für die Elektromobilität wichtige Komponenten, bei denen die Pulvertechnologie noch eine bedeutende Rolle spielen dürfte.

Klar ist: Hochleistungswerkstoffe werden sich durchsetzen. 